\title{
Atrial Fibrillation and Shock: Unmasking Theophylline Toxicity
}

\author{
Efi Aggelopoulou ${ }^{\mathrm{a}}$ Stavros Tzortzis $^{\mathrm{b}} \quad$ Fotini Tsiourantani $^{\mathrm{a}} \quad$ Ioannis Agrios $^{\mathrm{b}}$ \\ Kyriakos Lazaridis ${ }^{b}$ \\ a 3rd Department of Internal Medicine, 417 Army Share Fund Hospital, Athens, Greece; bepartment of Cardiology, \\ 417 Army Share Fund Hospital, Athens, Greece
}

\section{Significance of the Study}

- An unusual clinical course in common diseases may be indicative of medication toxicity for which therapeutic intervention is potentially curative. People who attempt suicide frequently conceal the offending medication, and clinicians must comprehensively identify medications that patients may have access to in order to ensure that a medication-related cause for the presentation is not overlooked.

\section{Keywords}

Atrial fibrillation · Shock · Theophylline toxicity

\section{Abstract}

Objective: The aim of this report is to describe a case of atrial fibrillation and shock precipitated by deliberate self-poisoning with theophylline. Clinical Presentation and Intervention: An 85-year-old male with severe theophylline intoxication in a suicide attempt was admitted with severe cardiac arrhythmia and shock; despite poor prognosis, he fully recovered gradually after proper diagnosis and treatment. Theophylline is a rather forgotten medication; thus, intoxication is not usually considered among the etiologies of potentially treatable cardiologic emergencies, especially when its use is intentionally concealed. Conclusion: This case highlights the importance of identifying a comprehensive medication history using all available sources of information as early as possible in an emergency department presentation.

(c) 2018 The Author(s)

Published by S. Karger AG, Basel

\section{KARGER}

E-Mail karger@karger.com www.karger.com/mpp

\section{(C) 2018 The Author(s)}

Published by S. Karger AG, Basel

Karger

Open access

This is an Open Access article licensed under the Creative Commons Attribution-NonCommercial-4.0 International License (CC BY-NC) (http://www.karger.com/Services/OpenAccessLicense), applicable to the online version of the article only. Usage and distribution for commercial purposes requires written permission.

\section{Introduction}

Atrial fibrillation is a common cause of admission to the emergency department (ED). Current data focus on genetic and lifestyle factors as the main causes of atrial fibrillation (AF) [1,2]. Theophylline (1,3-dimethylxanthine), a natural ingredient of cocoa and tea, has been used for years as a bronchodilator [3]. Its usage has diminished dramatically over the last couple of decades because of its frequently observed adverse effects as well as the introduction of more effective inhaled agents in the treatment of airway diseases [3]. Despite common knowledge that theophylline intoxication is potentially life-threatening, mainly due to severe cardiac arrhythmias, refractory hypotension, and convulsions [3-5], it is not usually considered among the etiologies of potentially curable cardiologic emergencies because of its limited use.
Efi Aggelopoulou

3rd Department of Internal Medicine, 417 Army Share Fund Hospital

Monis Petraki 10-12

GR-115-21 Athens (Greece)

E-Mail efi.angelo@gmail.com 


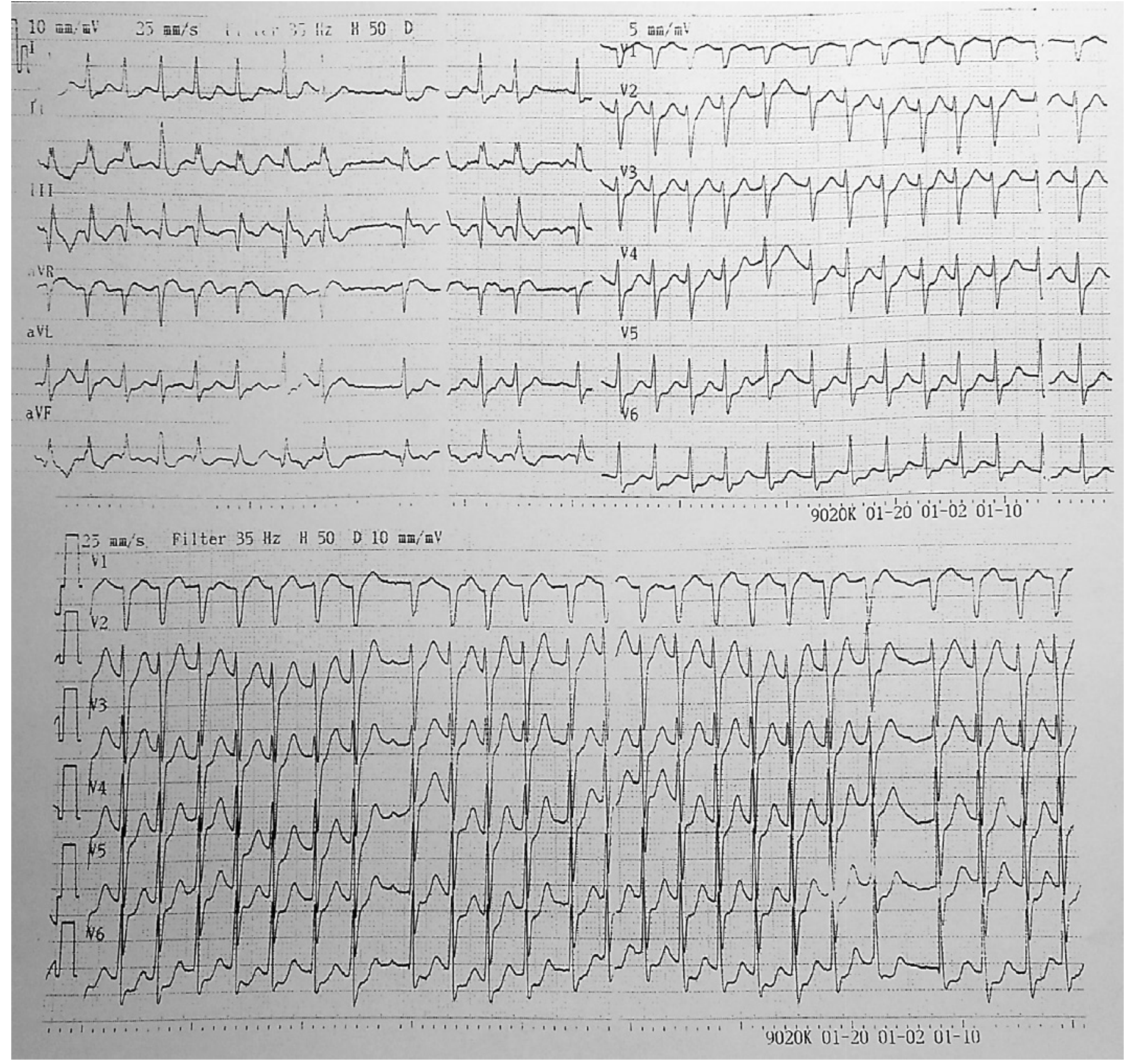

Fig. 1. ECG upon presentation.

\section{Case Report}

An 85-year-old male was admitted to the ED due to palpitations, generalized discomfort, and nausea. He was afebrile, tachycardic (140 bpm), with moist skin, and a blood pressure (BP) of $110 / 55 \mathrm{~mm} \mathrm{Hg}$. Physical examination revealed no significant signs from the lungs and the abdomen. He had a history of hypertension and chronic obstructive pulmonary disease and men- tioned taking amlodipine $5 \mathrm{mg}$. His electrocardiogram revealed AF with rapid ventricular response (Fig. 1). The echocardiogram showed a hypercontractile left ventricle with mild concentric hypertrophy, mild biatrial enlargement, mild-to-moderate tricuspid regurgitation and a pulmonary artery systolic pressure of $40 \mathrm{~mm}$ Hg. He had hypokalemia, and arterial blood gases showed mild respiratory alkalosis (Table 1). The patient was transferred to the intensive care unit; amiodarone, verapamil, and digoxin were ad- 
Table 1. Laboratory results upon presentation

\begin{tabular}{|c|c|c|c|}
\hline Test & Result & $\begin{array}{l}\text { Reference } \\
\text { range }\end{array}$ & Units \\
\hline \multicolumn{4}{|l|}{ Complete blood count } \\
\hline WBC & 12.2 & $4.0-10.0$ & $\mathrm{~K} / \mu \mathrm{L}$ \\
\hline Hct & 40.6 & $38.0-52.0$ & $\%$ \\
\hline $\mathrm{Hgb}$ & 14 & $13.0-18.0$ & $\mathrm{~g} / \mathrm{dL}$ \\
\hline PLT & 223 & $140-450$ & $\mathrm{~K} / \mu \mathrm{L}$ \\
\hline \multicolumn{4}{|l|}{ Blood chemistry panel } \\
\hline Glucose & 319 & $70-110$ & $\mathrm{mg} / \mathrm{dL}$ \\
\hline Urea & 62 & $10-55$ & $\mathrm{mg} / \mathrm{dL}$ \\
\hline Creatinine & 1.4 & $0.7-1.4$ & $\mathrm{mg} / \mathrm{dL}$ \\
\hline $\mathrm{K}^{+}$ & 3.1 & $3.5-5.1$ & $\mathrm{mmol} / \mathrm{L}$ \\
\hline $\mathrm{Na}^{+}$ & 140 & $136-150$ & $\mathrm{mmol} / \mathrm{L}$ \\
\hline Total bilirubin & 0.47 & $0.20-1.10$ & $\mathrm{mg} / \mathrm{dL}$ \\
\hline Direct bilirubin & 0.28 & $0.10-0.50$ & $\mathrm{mg} / \mathrm{dL}$ \\
\hline Indirect bilirubin & 0.19 & $0.20-0.70$ & $\mathrm{mg} / \mathrm{dL}$ \\
\hline Amylase & 98 & $25-125$ & IU/L \\
\hline ALP & 46 & $40-140$ & $\mathrm{IU} / \mathrm{L}$ \\
\hline$\gamma$-GT & 10 & $10-50$ & $\mathrm{IU} / \mathrm{L}$ \\
\hline SGOT (AST) & 16 & $5-40$ & $\mathrm{IU} / \mathrm{L}$ \\
\hline SGPT (ALT) & 14 & $5-40$ & $\mathrm{IU} / \mathrm{L}$ \\
\hline LDH & 243 & $100-220$ & $\mathrm{IU} / \mathrm{L}$ \\
\hline $\mathrm{CK}$ & 143 & $24-170$ & $\mathrm{IU} / \mathrm{L}$ \\
\hline \multicolumn{4}{|l|}{ Coagulation panel } \\
\hline PT & 11.7 & & s \\
\hline INR & 1.11 & & \\
\hline APTT & 28.3 & $26.0-36.0$ & s \\
\hline \multicolumn{4}{|c|}{ Arterial blood gas analysis } \\
\hline $\mathrm{pH}$ & 7.436 & $7.350-7.450$ & \\
\hline $\mathrm{PO}_{2}$ & 91.6 & $80.0-100.0$ & $\mathrm{~mm} \mathrm{Hg}$ \\
\hline $\mathrm{PCO}_{2}$ & 26.6 & $35.0-45.0$ & $\mathrm{~mm} \mathrm{Hg}$ \\
\hline $\mathrm{CHCO}_{3}^{-}$ & 17.4 & $22.0-26.0$ & $\mathrm{mmol} / \mathrm{L}$ \\
\hline
\end{tabular}

WBC, white blood cells; Hct, hematocrit; Hgb, hemoglobin; PLT, platelets; ALP, alkaline phosphatase; $\gamma$-GT, gamma-glutamyl transpeptidase; SGOT, serum glutamate oxaloacetate transaminase; AST, aspartate aminotransferase; SGPT, serum glutamic pyruvic transaminase; ALT, alanine aminotransferase; LDH, lactate dehydrogenase; CK, creatine kinase; PT, prothrombin time; INR, international normalized ratio; APTT, activated partial thromboplastin time.

ministered as pharmacological conversion agents. However, he developed hypotension and became unstable and unconscious. Despite aggressive fluid administration, he remained hypotensive (systolic BP $50 \mathrm{~mm} \mathrm{Hg}$ ) and experienced vomiting and continuous diarrhea, so he was started on inotropic solution. Despite a 10 -h infusion of noradrenaline solution at an escalating dose, the patient did not respond, with an SBP at 50-60 $\mathrm{mm} \mathrm{Hg}$ and a heart rate of 150-156 bpm. Brain, chest, and abdomen computed tomography scans revealed no pathology. The absence of fever and profound causes that could justify the acute distress of the patient led to a more thorough examination of his drug-taking history. After careful searching, the patient's relatives found that he was also under theophylline treatment with extended-release tablets. A serum theophylline concentration was assessed immediately and found to be approximately 4 times the upper limit of the therapeutic range at $78.7 \mu \mathrm{g} / \mathrm{mL}$ (reference range $10-20 \mu \mathrm{g} / \mathrm{mL}$ ). This concentration was noted about $10 \mathrm{~h}$ after his initial presentation to the ED. The administration of $0.05 \mathrm{mg} / \mathrm{kg} / \mathrm{min}$ of esmolol elevated his SBP to $95 \mathrm{~mm} \mathrm{Hg}$. Theophylline concentrations were normalized $(13.6 \mu \mathrm{g} / \mathrm{mL})$ after $24 \mathrm{~h}$. However, the patient developed acute renal failure and aspiration pneumonia. He was intubated and supported for 7 days. After his successful extubation, he was transferred to the internal medicine ward. He confessed that while being on theophylline treatment, he took a large quantity of tablets in a suicide attempt. He was discharged after 23 days of hospitalization, with sinus rhythm and a normalized renal function. He was prescribed inhaled corticosteroid/long-acting beta agonists for chronic obstructive pulmonary disease and was put under psychiatric surveillance. Informed consent was obtained from the patient.

\section{Discussion}

$\mathrm{AF}$ is a rather common cause of attendance to the emergency department $[1,2]$. Recent European Society of Cardiology guidelines focus on genetic, lifestyle, and comorbidity factors as central causes of AF, dedicating an extended report to them $[1,2]$. Medications are also recognized among the etiologies of AF [2]. Theophylline is a drug with a narrow therapeutic index, profound cardiotoxicity, and is in limited use nowadays, so only seldom is it considered a medication causing cardiac arrhythmias [2, 3]. Physicians do not readily recognize the clinical signs of its toxicity despite it being common knowledge. According to our review of the literature, sporadic cases of theophylline intoxication have been published until recently. They invariably represent known users of the drug with toxicity [5-9]. It needs high clinical suspicion to recognize intoxication of an unknown user.

Theophylline was originally used as a bronchodilator but has rather little bronchodilatory activity that is observed at high plasma concentrations, although it is believed that it has a variety of anti-inflammatory effects. In summary, different mechanisms seem to mediate the pharmacological activity of theophylline: (i) antagonism of all adenosine receptor types, i.e., A1, A2A, A2B, and to a lesser extent $\mathrm{A} 3$; this competitive inhibition results in increased hormone release, such as norepinephrine; (ii) nonselective competitive inhibition of 2 isoenzymes of phosphodiesterase (PDE), mainly PDE-3 and to a lesser extent PDE-4; this results in relaxation of smooth muscle cells in the airways, i.e., bronchodilation; (iii) stimulation of calcium release from intracellular stores; 
and (iv) activation of histone deacetylase 2; prevents transcription of inflammatory genes that require the acetylation of histones for transcription to begin. Furthermore, IL-10 secretion, apoptosis of inflammatory cells (neutrophils, T cells), and modulation of GABA receptors are some proposed mechanisms of theophylline action. It acts as a diuretic, smooth muscle relaxant, cardiac, nervous system, and ventilator stimulant [3]. The observed stimulation of the respiratory center by theophylline and its ability to increase the force of contraction of diaphragmatic muscles may lead to deep and rapid breathing that could explain the respiratory alkalosis seen in theophylline overdose.

Theophylline is rapidly absorbed, metabolized in the liver, and excreted by the kidney. Therapeutic ranges are usually achieved between $10-20 \mu \mathrm{g} / \mathrm{mL}$. Toxic effects are often seen above $20 \mu \mathrm{g} / \mathrm{mL}$ plasma concentrations and are related to plasma concentrations in an acute overdose. Minor but frequent side effects include nausea, vomiting, gastrointestinal reflux, restlessness, and headache and may develop even at low plasma concentrations. More severe side effects, such as severe cardiac arrhythmias, hypotension, convulsions, and even death occur at higher theophylline concentrations (usually $80-100 \mu \mathrm{g} / \mathrm{mL}$ ). In chronic exposure, the levels could be lower (40-60 $\mu \mathrm{g} / \mathrm{mL})$. Hypokalemia, hypercalcemia, hyperglycemia, and acidosis are metabolic disturbances that commonly occur after an acute overdose [3].

Early recognition of theophylline intoxication can be lifesaving. Aggressive supportive care and early accurate risk assessment are key to improving clinical outcomes. Gastrointestinal decontamination with activated charcoal is initially done, ideally within the first hours of ingestion [4]. However, individualization is recommended at later stages or when the time of poisoning is not known.

Usually, effective antiemetics are required to improve the chance of tolerating the activated charcoal. We did not administer activated charcoal because the risk of aspiration was too high due to vomiting and because the time of ingestion was unknown.

The use of beta-blockers is an acceptable approach to control tachydysrhythmias in theophylline toxicity. It is recommended in cases of refractory hypotension unresponsive to aggressive fluid administration and conventional vasopressors. Hypotension may result from $\beta$ adrenergic stimulation, $\beta 2$-stimulated peripheral vasodilation, and decreased diastolic feeling secondary to tachycardia $[4,5]$.
We preferred esmolol due to its fast reversing action and cardioselectivity with minimal action on the beta- 2 airway receptors [5]. While charcoal hemoperfusion is more effective, standard hemodialysis is a suitable alternative in the management of severe theophylline toxicity, as it is generally more readily available and can be commenced more quickly, ideally before the patient begins to deteriorate. In this case, although neither method could be applied, there was a rapid reduction in the blood levels of theophylline within $24 \mathrm{~h}$; this probably reflects intense metabolism and vigorous support with excess volume of fluids. The main differential diagnosis was a thyroid storm. Lack of fever that is almost an invariable characteristic of thyroid storm, absence of prophecy of the eyebrows or ophthalmic muscle palsy, and normal to slowly increased tendon reflexes made this diagnosis unlikely. Subsequently, thyroid function test results excluded the possibility of increased thyroid function.

A secondary but important message highlighted by the case is that people who intend to commit suicide often conceal the relevant medication, creating a diagnostic challenge for their medical team.

\section{Conclusion}

Theophylline is a rather forgotten medication, so intoxication by this drug is not usually considered among the etiologies of treatable cardiac emergencies, particularly when its use is intentionally concealed. This case highlights that the correct interpretation of clinical signs and close monitoring of the patient remain the cornerstone of clinical medicine. Early identification of a patient's medication regimen prior to presentation can greatly assist in identifying potential medication-related causes for an ED presentation.

\section{Disclosure Statement}

The authors declare that they have no conflicts of interest to disclose. 


\section{References}

1 Staerk L, Sherer JA, Ko D, et al: Atrial fibrillation: epidemiology, pathophysiology, and clinical outcomes? Circ Res 2017;120:15011517.

2 Kirchhof P, Benussi S, Kotecha D, et al: 2016 ESC Guidelines for the managment of atrial fibrillation developed in collaboration with EACTS? Eur Heart J 2016;37:2893-2962.

3 Barnes PJ: Theophylline? Am J Resp Crit Care Med 2013;188:901-906.
4 Minton NA, Henry JA: Treatment of theophylline overdose? Am J Emerg Med 1996;14: 606-612.

5 Seneff M, Scott J, Friedman B, et al: Acute theophylline toxicity and the use of esmolol to reverse cardiovascular instability? Ann Emerg Med 1990;19:671-673.

6 Shannon M: Life-threatening events after theophylline overdose: a 10-year prospective analysis? Arch Intern Med 1999;159:989-994.

7 Kapoor S, Thakkar J, Aggarwal V: Theophylline toxicity leading to suicidal ideation in a patient with no prior psychiatric illness. SAGE Open Med Case Rep 2015;22: $2050313 X 15583208$.
8 Hopkins ME, MacKenzie-Ross RV: Case report: the risks associated with chronic theophylline therapy and measures designed to improve monitoring and management? BMC Pharmacol Toxicol 2016;17:13.

9 Ichikawa K, Wada T, Nishihara T, et al: A case of life-threatening supraventricular tachycardia storm associated with theophylline toxicity? J Cardiol Cases 2017;15:125-128. http:// dx.doi.org/10.1016/j.jccase.2016.12.004. 